\title{
An Atomically Defined Iron Carbide Surface for Fischer-Tropsch Synthesis Catalysis
}

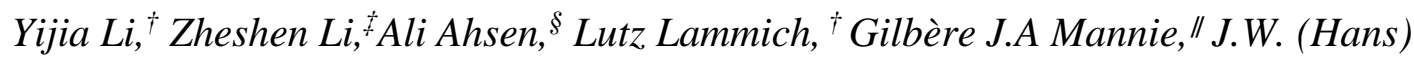

Niemantsverdriet, ${ }^{\prime \prime}, \perp$ Jeppe V. Lauritsen ${ }^{\dagger, *}$

†Interdisciplinary Nanoscience Center, Aarhus University, DK-8000 Aarhus C, Denmark.

¥Institute for Storage Ring Facilities, Aarhus University, 8000 Aarhus, Denmark.

§Department of Physics, Science Faculty, Gebze Institute of Technology, 41400 Gebze, Kocaeli, Turkey.

॥SynCat@Beijing, Synfuels China Technology Co. Ltd., Huairou, Beijing 101407, China.

\SynCat@DIFFER, Syngaschem BV, PO Box 6336, 5600 HH, Eindhoven, The Netherlands.

\begin{abstract}
With the purpose of investigating the reactivity of Fe carbide as active phase in Fischer-Tropsch catalysis, we study the formation of a well-defined Fe carbide surface structure resulting from carbon exposure of an Fe film on Au(111). Using two different sources of carbon (C), namely atomic carbon and ethylene gas, we use synchrotron X-ray photoelectron spectroscopy (XPS) to
\end{abstract}


show that a 6 ML Fe film readily converts into a well-defined and thermodynamically stable carbide phase. Scanning tunneling microscopy (STM) shows that the surface of the Fe carbide film is crystalline and dominated by Fe(110)-like facets perturbed into a (2×2) periodic structure due to insertion of $\mathrm{C}$ in the interstitial sites. The reactivity of the carbide film towards $\mathrm{CO}, \mathrm{H}_{2}$ and $\mathrm{O}_{2}$ was furthermore probed by XPS under vacuum conditions. While the pristine Fe carbide surface was unreactive towards hydrogen gas at $500 \mathrm{~K}$, we interestingly find that CO dissociation from a pre-adsorbed monolayer of $\mathrm{CO}$ takes place already at low temperature. This observation points to an intrinsic activity of the Fe carbide phase where additional carbon originating from $\mathrm{CO}$ can be placed in the Fe carbide surface. The catalytic significance of the model catalyst surface presented here is that it can be seen as a stable Fe-carbide phase with intrinsically vacant sites for additional C insertion at elevated pressure, and we propose that such additional C may act as active species in C-C coupling reactions during FTS. The studies pave the way for a better understanding of FTS processes on Fe-based catalysts based on a welldefined model surface.

KEYWORDS: Fischer-Tropsch Synthesis, Iron carbide, Carburization, Model Catalyst, X-ray Photoelectron Spectroscopy, Scanning Tunneling Microscopy

\section{Introduction}

The Fischer-Tropsch synthesis (FTS) process is applied to hydrogenate carbon monoxide (CO) in syngas to a wide spectrum of hydrocarbons that may be used as clean fuels and feedstock for chemicals. ${ }^{1}$ Even though practically all Group VIII transition metals display CO hydrogenation activity, mainly iron and cobalt catalysts are applied in the FTS industry currently. ${ }^{2,3}$ Fe-based 
catalysts have the advantage that they are cheap, have favorable selectivity in a broad temperature range (525-650K), with low methane make and substantial alkene yields at high temperatures. ${ }^{4}$ Furthermore, the Fe-based FTS catalysts have water-gas shift (WGS) capabilities - unlike Co, i.e. they catalyze the reaction between $\mathrm{CO}$ and $\mathrm{H}_{2} \mathrm{O}$ to form $\mathrm{H}_{2}$ and $\mathrm{CO}_{2}$. Through this reaction, one of the FTS products, $\mathrm{H}_{2} \mathrm{O}$, can be recycled to form $\mathrm{H}_{2}$, reducing the need of $\mathrm{H}_{2}$ in feedstock and adjusting the $\mathrm{H}_{2} / \mathrm{CO}$ ratio for hydrocarbon synthesis. Therefore, iron is the material of choice in FTS catalysts for syngas derived from coal or biomass, which has low $\mathrm{H}_{2} / \mathrm{CO}$ ratios. ${ }^{5}$

When exposed to FTS working conditions (typically $\mathrm{H}_{2}$, $\mathrm{CO}$ at 523-650 K and 10-50 bar), the $\mathrm{Fe}_{2} \mathrm{O}_{3}$ catalyst precursor particles are reduced, followed by subsequent carburization into active iron carbide phases, possibly only forming in the skin layer of the nanoparticles. ${ }^{6-9}$ The FTS activity has been directly linked with the formation of the iron carbide phases. ${ }^{8,10}$ However, the understanding of the active carbide phases is limited, as the nanoparticle structures are dynamic under catalytic operating conditions and there are several possible phases of iron carbides with varying carbon content, ${ }^{11}$ including Hägg carbide $\left(\mathrm{Fe}_{5} \mathrm{C}_{2}\right), \mathrm{Fe}_{7} \mathrm{C}_{3}$, cementite known from steel $(\theta-$ $\mathrm{Fe}_{3} \mathrm{C}$ ), $\varepsilon-\mathrm{Fe}_{2} \mathrm{C}$ and $\varepsilon^{\prime}-\mathrm{Fe}_{2.2} \mathrm{C} .{ }^{12-20}$ The bulk structure of iron carbides has been studied by crystallography and techniques like Mössbauer spectroscopy, high-resolution transmission electron microscopy (HRTEM), extended X-ray absorption fine structure spectroscopy (EXAFS), and X-ray diffraction (XRD), have been used for examining the structures of iron carbide particles. ${ }^{3,}$ 6, 7, 13, 18, 20-24 However, unlike in the case of Co-based catalysts, ${ }^{25-33}$ well-defined Fe carbide surfaces have not been studied other than in computational work, ${ }^{14-16,24,34-37}$ and the atomic-scale surface structures of iron carbides that are expected to play a role in catalysis has hardly been studied so far. 
Computational modeling has been applied to investigate possible FTS reaction steps on Fe carbide surfaces. It was proposed that the FTS overall reaction follows a Mars-van Krevelen (MvK) mechanism, which in the simplest case involves hydrogenation of carbidic carbon to $\mathrm{CH}_{3}$ monomers, liberation of carbon in the carbide surface, and dissociative adsorption of CO to fill the carbon vacancies, recovering the carbide surface. ${ }^{14-16}$ Surface science approaches have provided valuable atomic-scale verification of the MvK mechanism for catalytic CO oxidation on a number of transition metal catalyst surfaces. ${ }^{38-40}$ However, in lack of suitable Fe carbide model catalysts, experimental studies to investigate the catalytic mechanism have not yet been carried out for Febased FTS catalysts.

To shed light on the nature of active $\mathrm{C}$ species and their location in the surface of the iron carbide layers, the purpose of this study was to investigate how carburization proceeds in the skin-layer of an Fe film model system and then to characterize the morphology, atomic-scale structure and reactivity of the resulting Fe carbide surface towards $\mathrm{H}_{2}, \mathrm{CO}$ and $\mathrm{O}_{2}$. For this purpose we have synthesized multilayer iron carbide (> 6ML) thin films on $\mathrm{Au}(111)$, and characterized the formation process and resulting atomic structure using synchrotron X-ray Photoelectron Spectroscopy (XPS) and Scanning Tunneling Microscopy (STM). The source of C for carburization of Fe in FTS is dissociated CO in the syngas mixture. However, the low pressure conditions combined with the fact that efficient $\mathrm{CO}$ dissociation on Fe is a complex process mediated by $\mathrm{H}_{2}$, did not allow for sufficient carburization from $\mathrm{CO}$ with the approach taken here. ${ }^{41}$ In order to simplify the experiment we instead used two other $C$ sources, namely physical vapor deposition of atomic $\mathrm{C}$ and dosing of ethylene gas, to facilitate Fe carbide formation. We find that the $\mathrm{C}$ incorporation into the Fe skin layer is facile and that a well-defined and saturated carbide film gradually develops during exposure to both types of carbon sources. From atom-resolved 
STM images, we deduce that the carbide structure involves $C$ placed in interstitial sites within the bcc Fe lattice. The incorporation of $\mathrm{C}$ leads to a perturbed $(2 \times 2)$ reconstructed $\mathrm{Fe}(110)$ surface at the top facet of the carbide phase. Based on reaction studies with hydrogen we conclude from XPS that the $\mathrm{C}$ species in the film are unreactive at $500 \mathrm{~K}$. In contrast, exposure to $\mathrm{CO}$ reveals that dissociation on the pre-formed carbide film takes place even at low temperatures, leading to population of additional carbidic $\mathrm{C}$ sites. This indicates that the Fe carbide film can activate CO and furthermore suggests that the most likely candidates for FTS active C species in the structure are carbon placed at vacant sites within the carbide film revealed here. The carbide surface is thermally very stable, but we find that strong oxidation of the carbide into Fe-oxides takes place upon exposure to oxygen. The possible role of such oxidation during FTS activation and operation at elevated pressure will be discussed.

\section{Experimental}

The experiments were performed in an ultra-high vacuum (UHV) chamber with a base pressure below $1 \times 10^{-10}$ mbar, equipped with a scanning tunneling microscope (Aarhus type $\mathrm{e}^{42}$ ) and facilities for in-situ synthesis of the Fe carbide model catalyst. A single-crystal Au(111) surface was used as substrate for the Fe film growth. To obtain a clean surface, the $\mathrm{Au}(111)$ was cleaned by cycles of Arion bombardment ( $2 \mathrm{keV}$ ) followed by annealing. The cleanliness of the surface was checked by atom-resolved STM. Fe films were synthesized by physical vapor deposition of Fe on $\mathrm{Au}(111)$ kept at room temperature. The Fe deposition was done by a multipocket e-beam evaporator (Oxford Applied Research, model EGCO4) under UHV conditions. The Fe deposition rate was calibrated from the STM image, giving a deposition rate of $0.48 \mathrm{ML} / \mathrm{min}$, where $1 \mathrm{ML}$ is defined to be equivalent to a full coverage of Fe on the Au(111). Carbon was supplied either by physical 
vapor deposition (PVD) of elemental carbon from a carbon rod (Goodfellow, 99.997\%) using the e-beam evaporator or from ethylene $\left(\mathrm{C}_{2} \mathrm{H}_{4}\right)$ gas. For PVD, the rate of carbon deposition was 0.02 $\mathrm{ML} / \mathrm{min}$, estimated from the carbon XPS signal by using the sensitivity factor (calculation shown in $\mathrm{S} 1$ ). $\mathrm{C}_{2} \mathrm{H}_{4}$ (AGA, 99.99\%) was introduced to the chamber through a leak valve by means of a directional doser in order to establish an elevated pressure locally on the sample, estimated to be 100 times higher than the background pressure measured by an ion gauge. The STM images were acquired in a constant-current mode at room temperature (RT) using a PtIr tip.

The XPS measurements were conducted at the Matline, beamline at the ASTRID2 synchrotron light source (Aarhus, Denmark), using the same synthesis method as in the separate STM setup. The initial Fe film morphology was checked at the beamline using a dedicated STM installed in the endstation chamber. For the Fe core level spectra, only minor chemical shifts were observed for Fe carbides as compared to pure Fe. In contrast, the high resolution C1s signal is very sensitive towards several different carbon species formed during the synthesis. All spectra were recorded at normal emission if not mentioned otherwise. For acquisition of the C1s, O1s and Fe3p region, photon energies of $380 \mathrm{eV}, 620 \mathrm{eV}$ and $150 \mathrm{eV}$ were used, respectively. The calibration of the binding energy (BE) scale was performed against the Fermi-edge for each photon energy.

\section{Results and discussion}

The approach taken here starts with deposition of metallic Fe to form a crystalline, multilayer Fe film on the $\mathrm{Au}(111)$ surface. Before we analyze the carburization process, we note that the thickness of the Fe films plays a crucial role for successful iron carbide formation. Fe films with a thickness less than 2 atomic layers showed no tendency to form Fe carbide in XPS studies irrespective of the $\mathrm{C}$ source used, while Fe films thicker than 3 atomic layers readily incorporate C (Figure S2). It was previously reported that a structural evolution from a close-packed fcc-like 
structure to a $b c c$ structure occurs in the Fe/Au(111) films with increasing thickness. ${ }^{43-46}$ The onset of this phase transformation is the formation of a trilayer structure in the $\mathrm{Fe} / \mathrm{Au}(111)$ films in terms of the rectangular-shape islands with (110) orientation, as determined by extensive LEED, STM and XRD data in earlier studies. ${ }^{43,44,46}$ We therefore conclude that an essential requirement for carbide formation is the generation of the third Fe layer and emergence of a $b c c$ structure in the films. The absent affinity towards incorporation of $\mathrm{C}$ in the mono and bilayer fcc-type film on $\mathrm{Au}(111)$ can be related to significant strain effects from the Fe/Au interface and lack of interstitial sites suitable for accommodating $\mathrm{C}$ in the thinnest films.

The STM images in Figure 1 show the unreacted Fe film surface after deposition of 6 ML Fe equivalent on $\mathrm{Au}(111)$ at $\mathrm{RT}$, which is used subsequently in this study for carburization studies. We use this 6 ML thickness to exclude the effect of the structural transition at lower Fe coverages and to generally minimize the influence of the Au substrate. The surface in this state is a closed Fe film, but not atomically smooth. The surface morphology consists of islands with a near rectangular outline, which consistent with previous XRD, LEED and STM studies of $\mathrm{Fe} / \mathrm{Au}(111),{ }^{43,44,46}$ that identified the atomically flat top-facets in Figure $1 \mathrm{~b}$ as (110) terminated bcc-Fe.
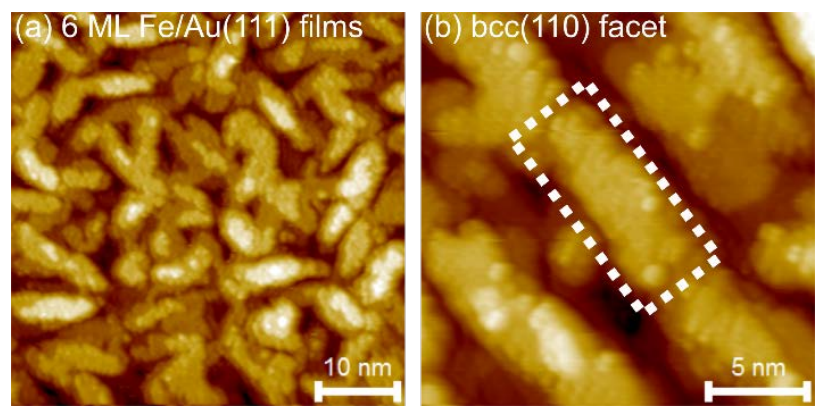

Figure 1. (a) Large-scale STM image recorded after 6 ML Fe deposition on $\mathrm{Au}(111)$ at $\mathrm{RT}\left(\mathrm{V}_{\mathrm{t}}=\right.$ $\left.-0.12 \mathrm{~V}, \mathrm{I}_{\mathrm{t}}=-0.17 \mathrm{nA}\right)$. (b) Magnification of the topmost bcc Fe(110) facet $\left(\mathrm{V}_{\mathrm{t}}=-0.63 \mathrm{~V}, \mathrm{I}_{\mathrm{t}}=-\right.$ $0.11 \mathrm{nA})$. 


\subsection{Fe carbide formation by atomic $\mathrm{C}$ deposition}

In order to explore the carburization process, we firstly monitored the formation of iron carbides by atomic $\mathrm{C}$ deposition. XPS measurements were performed to analyze the types of $\mathrm{C}$ species present in the sample and monitor the generation of carbides in the epitaxial Fe layers. The XPS data in the lower panel of Figure 2a shows the C1s peak acquired directly after 0.4 ML C deposition at RT. Already at this temperature, we see evidence for Fe carbide formation. In the deconvoluted XPS spectrum, there are several types of $\mathrm{C}$ contributing to the C1s signal. The peak structure can be fitted by three components with binding energies (BEs) located at $283.0 \mathrm{eV}, 284.2 \mathrm{eV}$ and 285.3 $\mathrm{eV}$, respectively. According to the reported C1s BEs (Table S1), the peak with the lowest BE at $283.0 \mathrm{eV}$ can be assigned to C-Fe bonds (i.e. carbidic C), suggesting the creation of iron carbide in the top layers of the sample. ${ }^{47,48}$ The middle peak at $284.2 \mathrm{eV}$ can be assigned to $\mathrm{sp}^{2}$ hybridized C (i.e. graphitic C), ${ }^{4-52}$ while the peak with the highest BE, shifted from the $\mathrm{sp}^{2}$ peak by around 1 $\mathrm{eV}$, is identified as $\mathrm{sp}^{3}$ hybridized $\mathrm{C}$ (similar to amorphous $\mathrm{C}$ ). ${ }^{20}$ All three peaks in this plot are fitted with a FWHM of $1.05 \mathrm{eV}$. The BEs of the $\mathrm{sp}^{2}$ and $\mathrm{sp}^{3} \mathrm{C}$ components agree well with the reported values, whereas the $\mathrm{BE}$ of carbide has a slight shift of around $0.4 \mathrm{eV}$ towards lower $\mathrm{BE}$ (Tab. S1). ${ }^{20,47-52}$ This difference may originate from a differences between the thin films used here

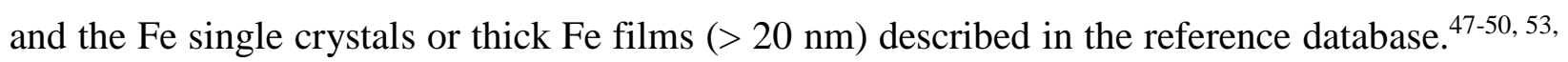
54 The formation of a significant carbide signal by elemental C deposition on multilayer Fe films exposing the (110) surface already at room temperature, indicates that incorporation of $\mathrm{C}$ in the $\mathrm{Fe}$ film through this facet is a thermodynamically facile process. 


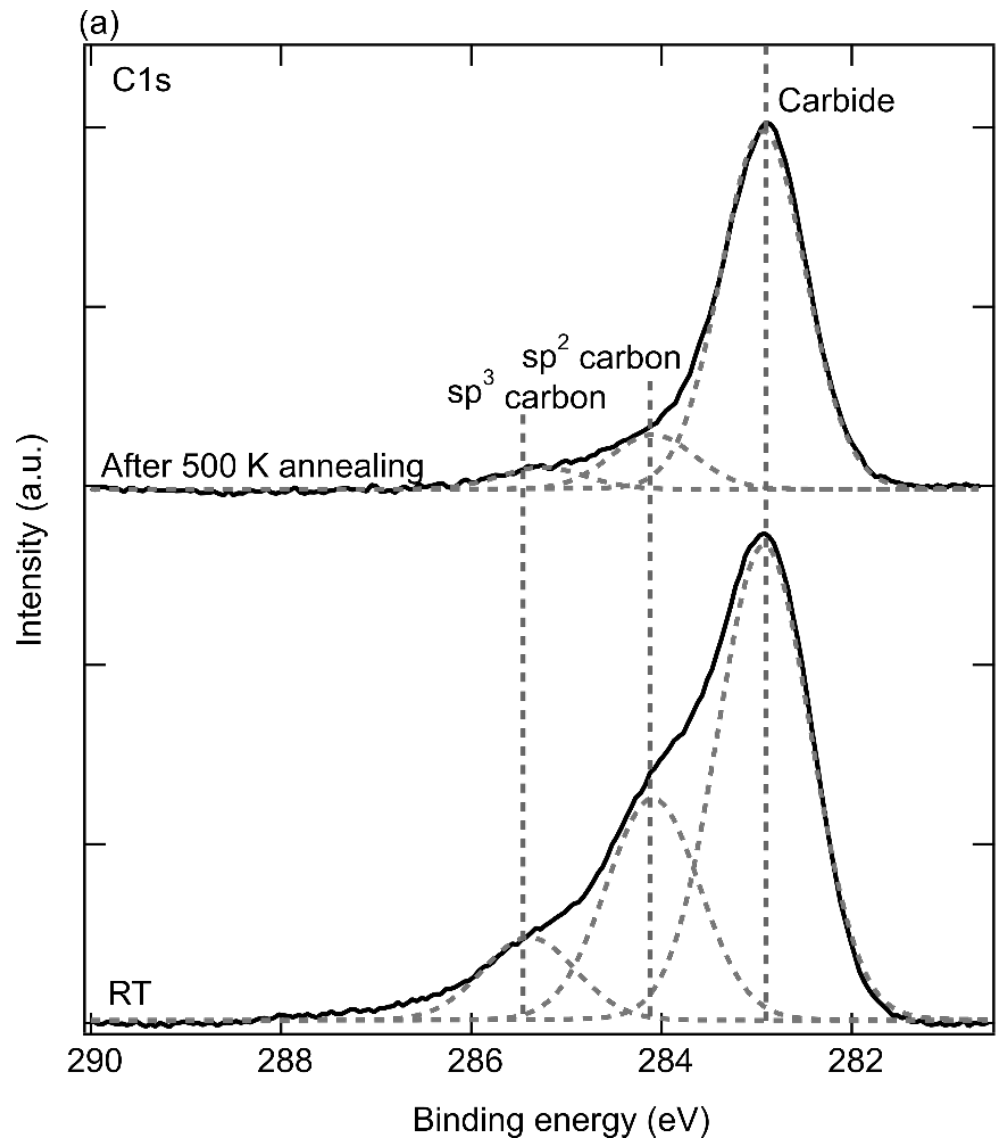

(b)

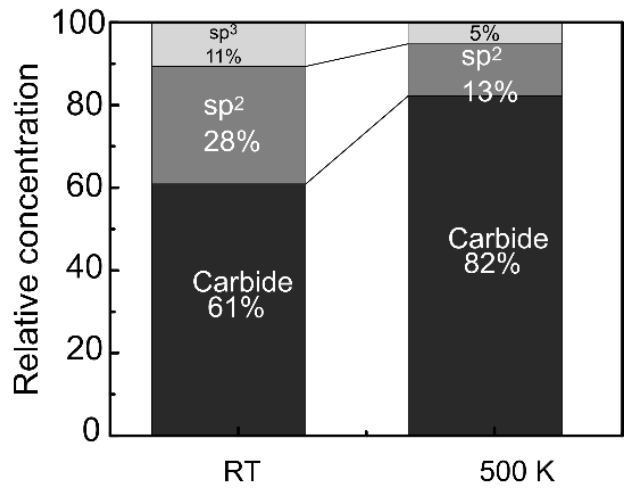

(c)

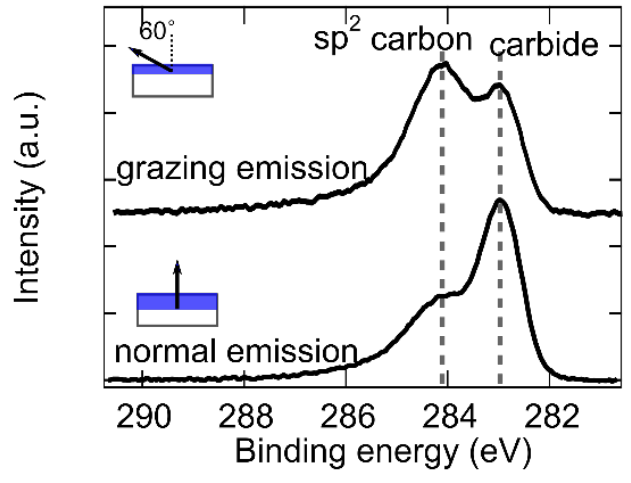

Figure 2. Carburization with atomic C deposition. (a) C1s XPS spectra after C deposition on $\mathrm{Fe} / \mathrm{Au}(111)$ : (lower) at room temperature, (upper) after subsequent annealing to $500 \mathrm{~K}$. The C1s spectrum contains three peaks, which are assigned to carbide, $\mathrm{sp}^{2}$ and $\mathrm{sp}^{3}$ hybridized C. (b) The relative contribution based on the area of the different components. (c) Angle-resolved C1s signal for the carbide sample synthesized by room temperature $C$ deposition. The photon energy for the C1s spectra was $380 \mathrm{eV}$.

The C1s core level spectra after annealing at $500 \mathrm{~K}$ in Figure 2a (upper panel) show that the relative intensities are significantly changed by thermal activation. The BE positions of the individual C1s components are unchanged, but both the graphitic $\mathrm{C}$ and amorphous $\mathrm{C}$ peak intensities decrease with respect to the carbide peak upon annealing, resulting in a more pronounced carbide peak (82\%) compared to the RT state (61\%). This change in relative concentration upon annealing is 
attributed to a conversion from graphitic surface $\mathrm{C}$ and amorphous $\mathrm{C}$ to carbidic $\mathrm{C}$ due to the activation of $\mathrm{C}$ diffusion from the surface and inwards. The angle-resolved XPS measurements of the C1s signal comparing normal emission with a grazing emission spectrum in Figure 2c confirm that the initial graphitic $\mathrm{C}$ resides predominantly at the surface. A reduction in the total intensity by $48 \%$ compared to the RT carbide films is also observed in Fig 2a, indicating that the annealing temperature of $500 \mathrm{~K}$ is enough for the formation of carbide in the deeper Fe layers beyond the probing depth in XPS (4.39 Å for the chosen photon energy).

The XPS results thus show that Fe carbide formation in the film is thermodynamically favored, but at lower temperature the limited diffusion of $\mathrm{C}$ from the surface into the Fe films prevents formation of carbides and leads to formation of the graphitic surface species. The preferential formation of Fe carbide agrees well with theory studies reporting that formation of carbide is more favorable than graphite on $\mathrm{Fe}(110) .{ }^{54-56}$ The temperature needed to activate $\mathrm{C}$ diffusion in Figure 2a is in agreement with $\mathrm{C}$ diffusion in Fe, which is an activated process with a predicted energy barrier of $0.86 \mathrm{eV}$ for interstitial $\mathrm{C}$ diffusing from one interstitial site to another in the bulk of ferrite. ${ }^{57}$ We speculate that $\mathrm{C}$ atoms occupy all interstitial sites close to the surface during the first stages of deposition at RT, and further deposited C atoms can only accumulate on the surface giving rise to the $\mathrm{sp}^{2} \mathrm{C}$ peak. At elevated temperature, this restriction is lifted and the carbide formation takes place also in deeper layers. In agreement with the experiment, theoretical modeling also suggested graphite formation caused by significant repulsion between $\mathrm{C}$ atoms on $\mathrm{Fe}(110)$ at high coverage, after carbide formation. ${ }^{55,56}$ 


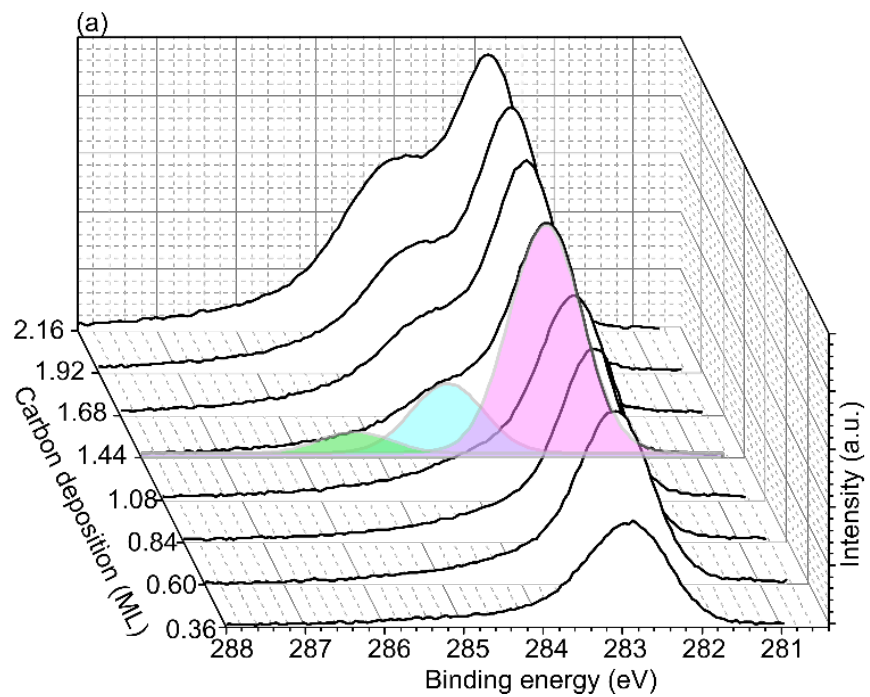

(b)

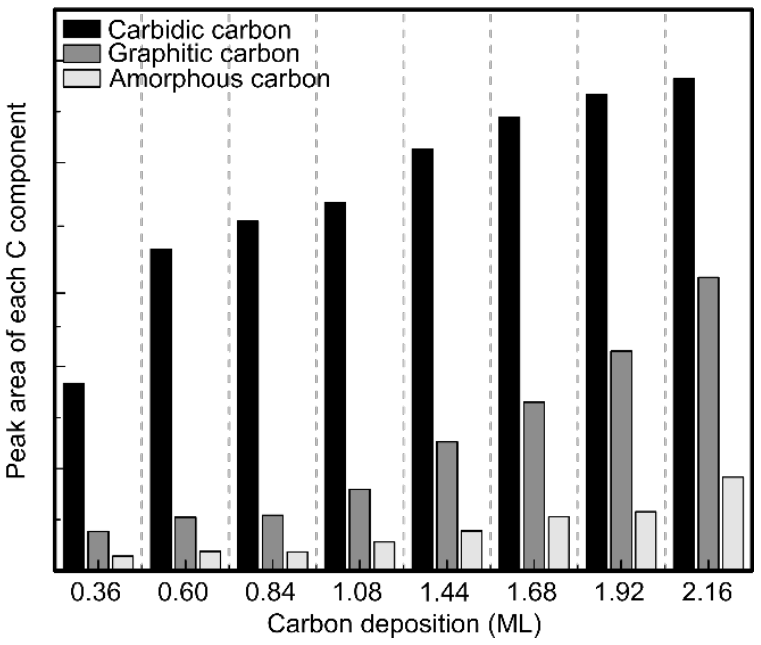

Figure 3. Carburization with atomic C deposition. (a) Waterfall diagram illustrating the gradual changes in the C1s signal plotted as a function of $\mathrm{C}$ deposition. For sake of clarity, the fitted spectrum for the different carbon species is only displayed for 1.44 ML C. (b) Contribution of each C component in the C1s spectra.

A saturated carbide phase can be synthesized by several cycles of deposition and annealing. A series of XPS experiments following 8 cycles of $\mathrm{C}$ deposition and $500 \mathrm{~K}$ post-annealing was performed in order to explore the conversion of the metallic Fe film into a saturated carbide phase. A waterfall diagram illustrating the gradual changes in the C1s signal is plotted as a function of deposited C amount in Figure 3a. The corresponding evolution of fitted peak areas shown in Figure 3b illustrates, that the carbide peak (283 eV), appears in the first cycle and increases in intensity by more than $100 \%$ with further $\mathrm{C}$ deposition. For the first three cycles, the graphitic peak is mostly absent after annealing, due to in-ward diffusion of C. For the subsequent cycles ( $\geq 1.44 \mathrm{ML} \mathrm{C}$ ), the $\mathrm{sp}^{2}$ graphitic and $\mathrm{sp}^{3}$ amorphous $\mathrm{C}$ peak increases, indicating that the $\mathrm{C}$ amount in the Fe film has reached saturation under the conditions of the experiment. Fe carburization followed by $\mathrm{C}$ precipitation is also reported in the literature on nanoparticle samples. ${ }^{58}$ It is possible to estimate the Fe:C ratio in the saturated carbide phase from a quantitative XPS analysis of the Fe3p and C1s 
spectra. We used a procedure where the area of Fe3p and the carbide component of the C1s spectra are measured and corrected by an experimentally obtained sensitivity factor (calculation shown in S1). For the saturated films obtained by atomic C deposition, this quantitative XPS analysis results in an average Fe:C ratio of $6.7 \pm 0.6$ (corresponding to carbon content of $13.2 \pm 1.1$ at\%).

\subsection{Fe carbide formation by ethylene decomposition}

Figure 4 shows the C1s core level spectra for a carbide film where the $\mathrm{C}$ source was $\mathrm{C}_{2} \mathrm{H}_{4}$ gas instead. In this experiment, we dosed $\mathrm{C}_{2} \mathrm{H}_{4}$ at $\sim 3 \times 10^{-3}$ mbar (using a directed doser) to a freshly prepared Fe multilayer film while the sample temperature was 500K (Figure 4a) and 300K (Figure 4b). Again, the C1s signal resulting from the decomposition of $\mathrm{C}_{2} \mathrm{H}_{4}$ on the surface of Fe films at $500 \mathrm{~K}$, can be deconvoluted into three peaks fitted with a FWHM of $1.05 \mathrm{eV}$, consistent with the assignment of carbidic species and C surface species as before. As illustrated in Figure 4, all peak intensities for $500 \mathrm{~K} \mathrm{C}_{2} \mathrm{H}_{4}$ decomposition are significantly higher than at $300 \mathrm{~K}$, reflecting that decomposition of ethylene is more efficient at high temperature, as expected. We note that, the C1s spectrum after $300 \mathrm{~K} \mathrm{C}_{2} \mathrm{H}_{4}$ exposure is slightly shifted towards the higher $\mathrm{BE}$ side as illustrated in Figure 4b. Furthermore, the three peaks are fitted with a larger FWHM of $1.25 \mathrm{eV}$. We associate this shift of $\mathrm{BE}$ and the broader peaks to the incomplete dehydrogenation of $\mathrm{C}_{2} \mathrm{H}_{4}$ on $\mathrm{Fe} / \mathrm{Au}(111)$ at $\mathrm{RT},{ }^{59}$ leading to more complex $\mathrm{C}$ states on the sample surface. 


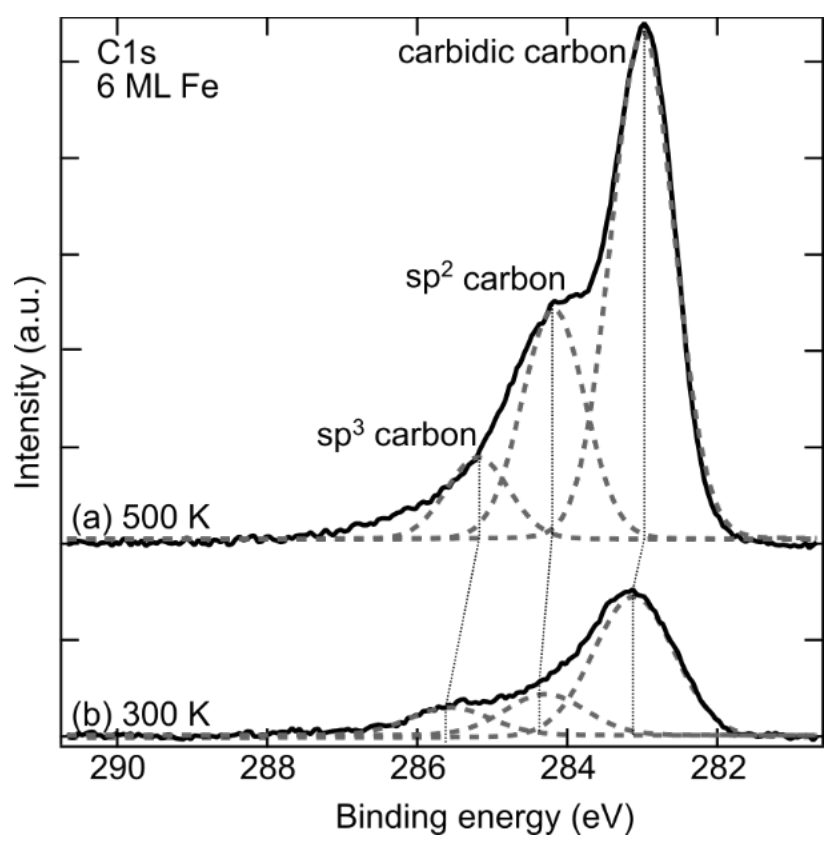

Figure 4. Carburization with $\mathrm{C}_{2} \mathrm{H}_{4}$ gas. C1s XPS spectra following $\mathrm{C}_{2} \mathrm{H}_{4}$ exposure at a pressure of $3 \times 10^{-3}$ mbar for $20 \mathrm{~min}$ at $500 \mathrm{~K}(\mathrm{a})$ and $300 \mathrm{~K}(\mathrm{~b})$.

The C1s spectra reflecting the gradual $\mathrm{C}$ uptake as a function of $\mathrm{C}_{2} \mathrm{H}_{4}$ dosage are compiled as a waterfall plot in Figure 5a. Only the first experiment was undertaken at RT, and the rest were at $500 \mathrm{~K}$. The peak areas for different C phases gained from XPS fitting are presented in Figure 5b. A similar trend as for the atomic $\mathrm{C}$ deposition method is observed for $\mathrm{C}_{2} \mathrm{H}_{4}$ decomposition, with the growth of carbidic C first and graphite after several cycles. Moreover, the carbide films with different $\mathrm{C}$ content show various reactivity towards $\mathrm{C}_{2} \mathrm{H}_{4}$. Although the total peak area (I) in Figure 5c increases after each $\mathrm{C}_{2} \mathrm{H}_{4}$ annealing step, the $\mathrm{C}$ uptake efficiency ( $\Delta \mathrm{I} /$ cycle) decreases significantly after the first two steps. This reflects that the initially metallic Fe(110) surface exhibits the highest rate for $\mathrm{C}_{2} \mathrm{H}_{4}$ decomposition, while the carbide surfaces exposed in subsequent steps show a declining activity for $\mathrm{C}_{2} \mathrm{H}_{4}$ decomposition with increasing $\mathrm{C}$ content in the Fe film. This observation suggests the importance of $C$ vacancies in the carbide films. A similar effect is seen when CO is considered as the source of $\mathrm{C}$ as earlier reported DFT calculations indicate that 
CO decomposition follows a trend opposite to the $\mathrm{C}$ content in the carbide films in relation to the available interstitial sites for $\mathrm{C}$ incorporation. ${ }^{15}$ The quantitative analysis of the $\mathrm{Fe}: \mathrm{C}$ ratio in the saturated carbide phase obtained by $\mathrm{C}_{2} \mathrm{H}_{4}$ dosing gives a similar value of $5.7 \pm 1.1$ (carbon content $15.3 \pm 2.6$ at\%) compared with the $\mathrm{C}$ deposition method. Within uncertainty, we assume the types of carbide formed by these two methods are the same. This C content is comparable with iron carbide films generated by magnetron sputtering of $\mathrm{Fe}$ and $\mathrm{C}$ targets onto a $\mathrm{Si}(001)$ surface $^{49}$
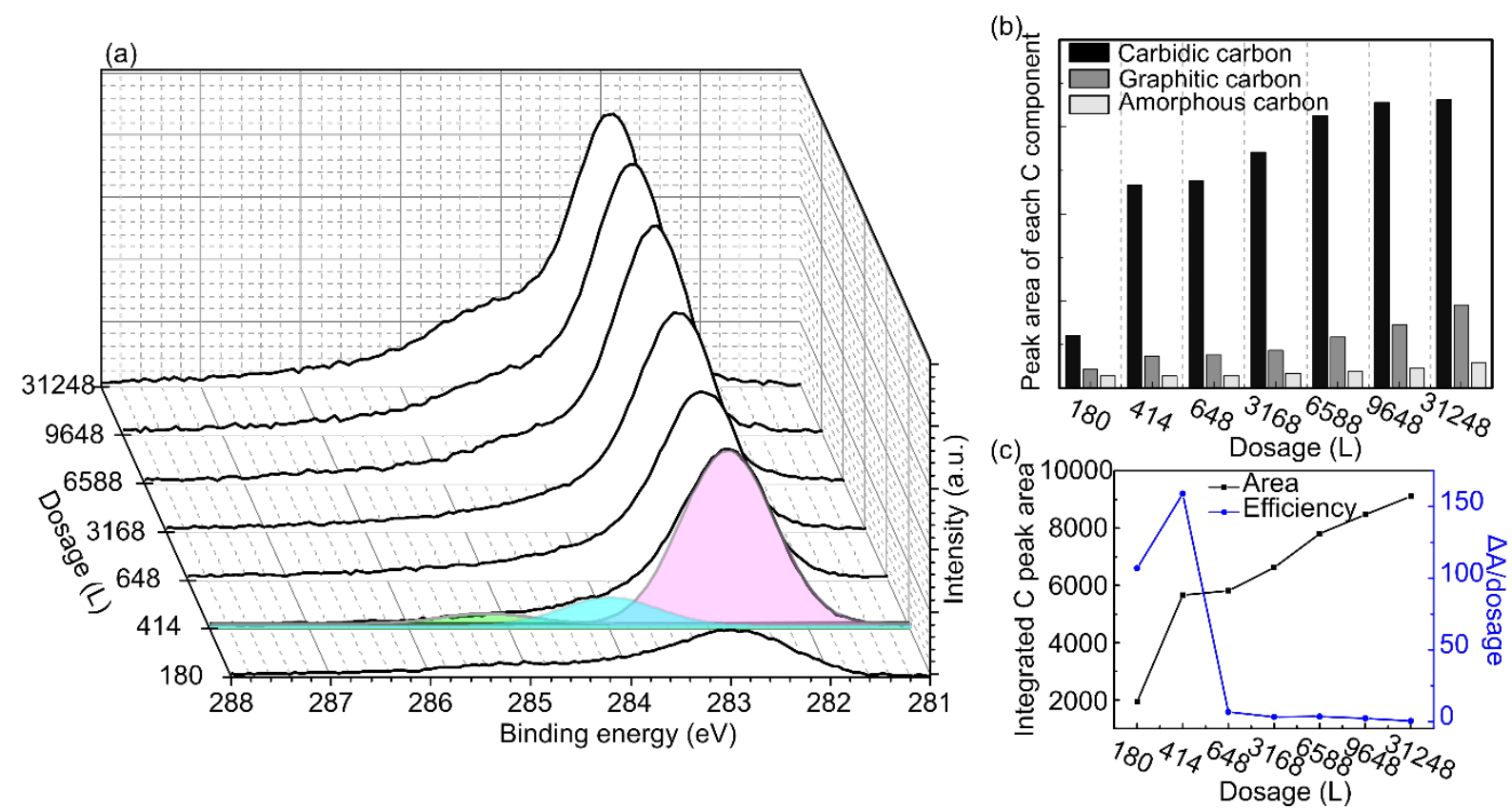

Figure 5. Carburization with ethylene gas. (a) Waterfall plot of the XPS spectra of the C1s region following a series of $\mathrm{C}_{2} \mathrm{H}_{4}$ annealing steps. (b) Contribution of different $\mathrm{C}$ components after each step. (c) Toal C uptake area I, and efficiency ( $\Delta \mathrm{I}$ pr. cycle) from $\mathrm{C}_{2} \mathrm{H}_{4}$ into $\mathrm{C}$ in the sample for each step.

\subsection{Scanning Tunneling Microscopy of the Fe-carbide surface}



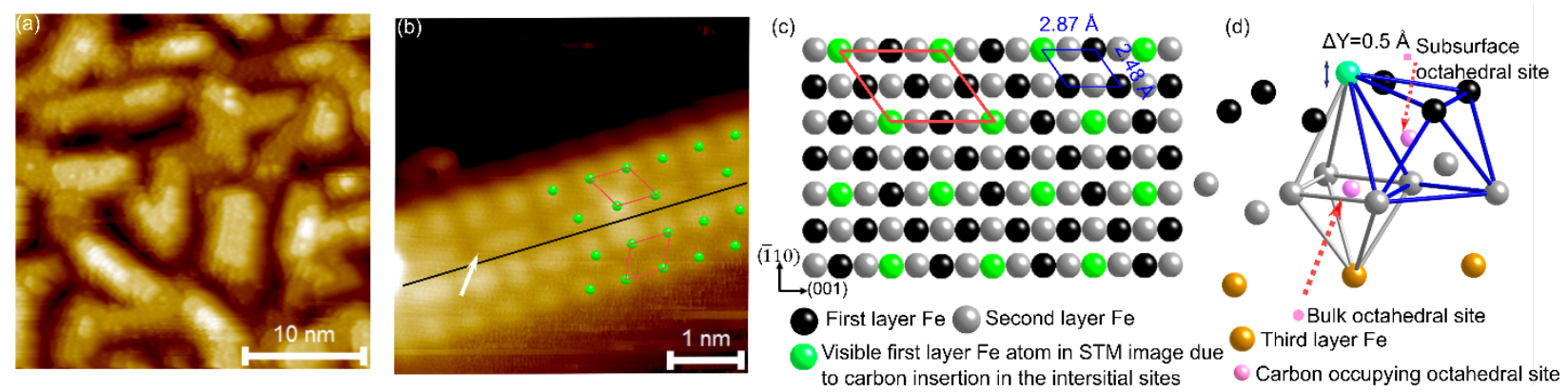

Figure 6. STM images of the Fe carbide film. (a) The morphology of the Fe carbide surface. (b) Zoom-in STM image of one of the facets $\left(\mathrm{V}_{\mathrm{t}}=-0.37 \mathrm{~V}, \mathrm{I}_{\mathrm{t}}=-0.56 \mathrm{nA}\right)$. (c) Top view ball model of the carbide surface with C atoms occupying every second octahedral interstitial sites, leading to a perturbed $(2 \times 2)$ reconstructed structure. (d) Illustration of the proposed octahedral interstitial sites for $\mathrm{C}$ atom incorporation. The on-top Fe atom is pushed toward the vacuum by $0.5 \AA$.

The STM images in Figure 6 display the structure of a saturated Fe carbide phase in a state before the formation of excessive amounts of graphitic $\mathrm{C}$ on the surface (i.e. near the $1.44 \mathrm{ML} \mathrm{C}$ deposition point in Figure 3a). A sequence of $\mathrm{C}$ deposition followed by $500 \mathrm{~K}$ post-annealing like in Figure 3 were performed. The comparison of the large-scale STM image displaying carbide surface in Figure 6a and Figure S3a with the pristine Fe film in Figure 1a shows that the overall morphology of the carbide film is unchanged after carburization, still exposing rectangular shaped and atomically flat facets. The unchanged large-scale morphology immediately suggests that carburization takes place without any large structural modifications and is consistent with C being incorporated in a facile way at interstitial sites in the Fe lattice. The atom-resolved STM image (Figure 6b) is a magnification of the top facet also shown in Figure S3a, which resolves that the surface on the atomic-scale consists of elongated facets with protrusions arranged in a periodic fashion that are not inherent to a clean and atomically flat $\mathrm{Fe}(110)$ surface. The most abundant atomic-scale motif is the rhombic unit cell superimposed on the image in Figure 6b. The unit cell 
exposes a distance between two protrusions along the long edge of $\sim 5.7 \AA$ (Figure S4) and $~ 5.0 \AA$ along the short edge. In the particular case shown Fig 6b, the symmetry of this rhombic repetition unit is mirrored in a line going along the long direction of the resolved facet. The observation of local order among some long range disorder was quite general for the top facets of the Fe carbide islands resolved in STM (see also Figure S3b).

The characteristic distances in the film structure are larger than the in-plane atomic distances of $\mathrm{Fe}(110),{ }^{47}$ but comparable with the larger lattice constants of carbides. ${ }^{6}$ In fact, the predominant rhombic unit cell observed Figure $6 \mathrm{~b}$ is a rather perfect match to a $(2 \times 2)$ reconstructed unit cell, based on the surface unit cell of Fe(110). This is illustrated by the ball model in Figure 6c showing the first layer Fe atoms as black balls and the second layer Fe atoms as grey balls. Here the $(2 \times 2)$ relation between the Fe(110) surface unit cell (blue rhomb) and the observed superstructure (green balls and red rhomb) is visualized. Based on this we can propose a tentative structural model for the observed carbide surface structure. The model is generated from the pristine Fe(110) surface, where we have evaluated structures with $\mathrm{C}$ atoms located in different interstitial sites in order to reproduce the geometry revealed in the STM. The (110) surface exposes two kinds of voids wherein $\mathrm{C}$ can be placed as indicated in Figure 6d: (i) bulk bcc octahedral sites underneath every topmost (black) Fe atom; ${ }^{57,60}$ (ii) a distorted subsurface octahedral site $\left(\mathrm{C}_{\mathrm{i}, \text { surf }}\right)$ revealed in theory studies ${ }^{55,49}$ which is located in between the first two layers. Evidently placing $C$ in each of these octahedral sites will lead to a distortion of the surrounding host bcc surface. The local range of this distortion means that $\mathrm{C}$ atoms can only favorably occupy every second of these octahedral interstitial sites in a plane parallel to the surface, thus forming a $(2 \times 2)$ periodicity. At the position of the $\mathrm{C}$ interstitial atom, strain is released by pushing the on-top surface Fe atom towards the vacuum (shown in green in Fig 6c). The displacement distance of the topmost Fe in similar 
geometries is estimated from theory to be $0.5 \AA,{ }^{55}$ which is in strong agreement with the corrugation shown in STM image (Figure 6b). From our structural STM observations alone, we cannot implicitly determine whether bulk octahedral sites or subsurface octahedral sites are occupied, as the $(2 \times 2)$ pattern can be built from structures that include either type of sites. We note however, that the irregularities commonly observed in the $(2 \times 2)$ structure, exemplified by the elongated protrusions marked by the white arrow in Fig 6b, could be due to a local combination of $\mathrm{C}$ atoms in bulk and subsurface octahedral sites or addition of $\mathrm{C}$ on additional vacant octahedral sites. Based on the surface model, we assume that the saturated Fe carbide film in deeper layers is built from repetition of such layers, where $\mathrm{C}$ takes up positions at the free sites underneath the center of the $(2 \times 2)$ unit cell, so that an alternating stacking of Fe layers with $\mathrm{C}$ in every fourth bulk octahedral sites is formed. Assuming full C saturation, this model gives an overall maximum carbon content of 20 at\%. The ideal structure is obviously higher in C content than the averaged concentrations ( $\sim 13.2$ at $\%$ for atomic C and $\sim 15.3$ at\% for ethylene deposition) deduced from the quantitative XPS analysis. This deviation from a perfect stoichiometry may reflect that C saturation was not fully achieved throughout the Fe film due to kinetic effects in the C migration and partial oxide formation (see below).

\subsection{Fe-carbide reactivity in $\mathrm{H}_{2}$ and $\mathrm{CO}$}

The saturated Fe carbide samples were first exposed to hydrogen gas, in order to study if $\mathrm{C}$ extraction by $\mathrm{H}_{2}$ is possible following the proposed MvK mechanism for FTS. However, as illustrated in the XPS results in Figure 7a, we very limited changes to the C1s spectrum relative to the as-prepared sample after annealing in $2 \times 10^{-6}$ mbar $\mathrm{H}_{2}$ at $500 \mathrm{~K}$. We conclude that the $\mathrm{Fe}$ carbide surface produced by the methods here is in a relatively unreactive state at this temperature, i.e. the lattice carbon is not easily removed by hydrogen under the conditions employed. Graphitic 
and amorphous carbon located on top of the carbide surface could in principle limit $\mathrm{H}_{2}$-carbide contact, but the STM results show that carbide patches are always exposed.
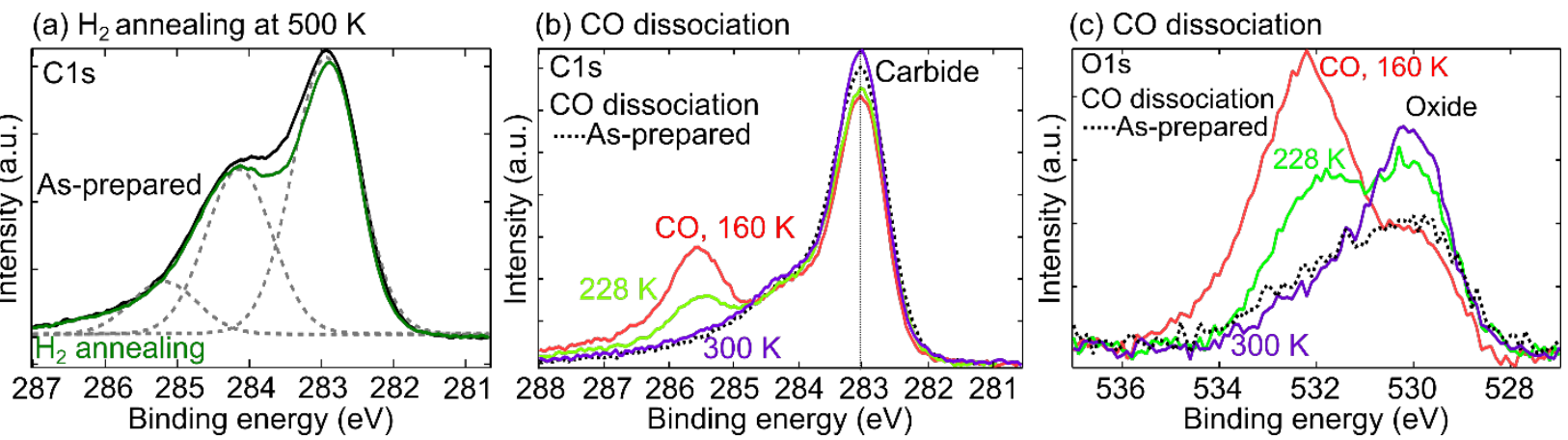

Figure 7. (a) Overlapped C1s XPS spectra after annealing the as-prepared iron carbide sample in hydrogen at $500 \mathrm{~K}$ and $2 \times 10^{-6}$ mbar. (b and c) C1s and O1s core level spectra after heating a COprecovered surface in steps from $160 \mathrm{~K}$ to $300 \mathrm{~K}$. The C1s peaks are labelled according to the assignment of $\mathrm{CO}$ and Fe carbide components. The O1s peaks are labelled according to $\mathrm{CO}$ and Fe oxide components. The initial O content is due to oxide formation during synthesis.

Instead, the negligible reactivity toward hydrogen of our model sample could also be due to the lower C content, compared with the reported values for carbides at FTS working conditions of 25 at\% $\left(\mathrm{Fe}_{3} \mathrm{C}\right), 28$ at\% $\left(\mathrm{Fe}_{5} \mathrm{C}_{2}\right)$, and 30 at\% $\left(\mathrm{Fe}_{7} \mathrm{C}_{3}\right){ }^{3}{ }^{32}{ }^{12}, 20$. We speculate that higher $\mathrm{C}$ levels may be reached by populating the intrinsically available sites in the Fe lattice in the structural model shown in Figure 6c under FTS conditions. A possible indication for this is provided by additional CO dissociation experiments on the pristine, saturated Fe carbide surface prepared by ethylene carburization as in Fig 5. Figures 7b and 7c show the C1s and O1s core level spectra, respectively, obtained during a temperature ramp in an experiment where $\sim 600 \mathrm{~L}$ of CO was pre-adsorbed at $160 \mathrm{~K}$ at $3 \times 10^{-6}$ mbar. At the lowest temperature (red curve) the C1s peak structure reflects the adsorbed CO by a component at high binding energy (285.6 eV), in addition to the peak components representing the graphitic and carbidic species in the saturated Fe carbide film from 
before. A comparison of the C1s spectrum obtained at the different temperatures (Figure 7b) shows a continuous decrease in the $\mathrm{CO}$ component located high binding energies and a concomitant change in the carbidic peak. The drop in the CO peak from low to high temperature is mainly due to $\mathrm{CO}$ desorption. While $\mathrm{CO}$ is still adsorbed, the carbide component of the $\mathrm{C} 1$ s peak is attenuated compared with the starting point (black) due to the screening of the adsorbed CO layer until it has desorbed completely at $300 \mathrm{~K}$. However, a direct comparison of the pristine (black) with the COexposed sample at $300 \mathrm{~K}$ reveals an increase of the carbidic peak. Accordingly, this effect is also observed in the O1s spectra in Figure 7c, where an "Fe oxide" peak at low binding energy develops after annealing at the expense of the $\mathrm{O}$ component from adsorbed CO. Both the carbide peak and oxide peak acquired after annealing show higher intensity than the as-prepared sample, indicating CO dissociation on the sample surface during the temperature ramp to $300 \mathrm{~K}$. Direct quantification of the C1s peak component areas yields an increase of 0.4 at $\%$ in the carbide peak compared to the as-prepared sample. Almost no change in the graphitic peak (middle part at $284.2 \mathrm{eV}$ ) is observed which confirms that the increase in XPS signal is due to carbide formation. CO dissociation on $\mathrm{Fe}(110)$ was reported to be very slow at room temperature. ${ }^{61}$ In agreement, when CO was dosed to a pure metal $\mathrm{Fe}(110)$ film at room temperature in our experiment, no corresponding reactivity towards $\mathrm{CO}$ under was found. The difference between $\mathrm{CO}$ for the pure metal and the carbide surface thus suggests the importance of the carbide phase in the activation of $\mathrm{CO}$ molecules and indicates that it is possible to adsorb additional carbon on the thermodynamically stable carbide surface prepared by ethylene decomposition. The experiment shows that the $(2 \times 2)$ structure is thermodynamically favorable even at the chemical potential of $\mathrm{C}$ used in the vacuum conditions, and we therefore suggest that the model can be viewed as a basic structure on which additional active $\mathrm{C}$ species are formed at elevated pressure. The proposed model 
in Fig 6b suggests that such active sites may be located within the $(2 \times 2)$ structure, which can be filled with C at regular bulk octahedral sites or subsurface octahedral sites in the subsurface layers. Such C atoms may be less strongly bound within the carbide structure and therefore also more reactive. The absolute increase in carbidic carbon content in the film resulting from the experiment in Figure 7b is quite moderate ( 0.4 at\%), but it is consistent with formation of carbidic carbon only in the surface layer due to limited mobility of the $\mathrm{C}$ at $300 \mathrm{~K}$. Further sites may be efficiently be filled by $\mathrm{C}$ at elevated pressure condition and temperatures corresponding to FTS, and we anticipate that such species can be confirmed spectroscopically under high-pressure FTS working conditions where the chemical potential becomes substantially favorable for additional C insertion in the iron lattice. Additional studies which include elevated pressure and high temperature conditions are needed to confirm these hypotheses.

\subsection{Fe-carbide reactivity in $\mathrm{O}_{2}$}
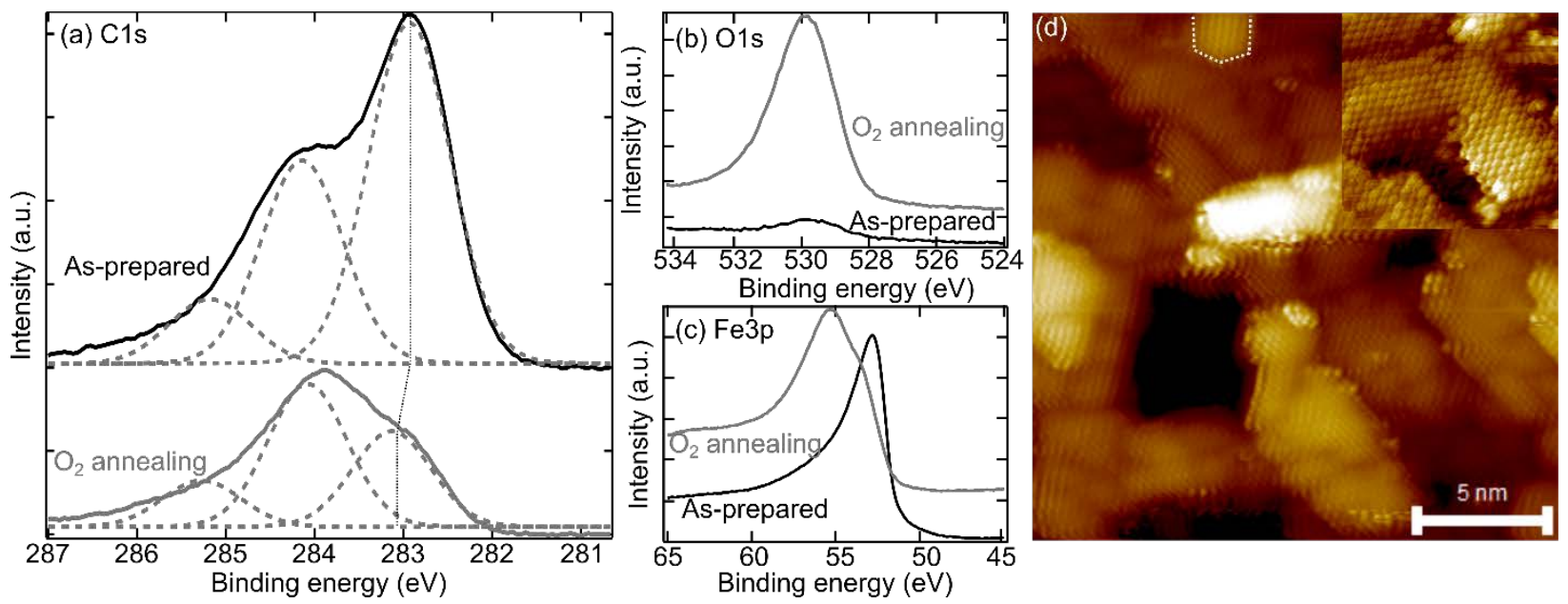

Figure 8. (a-c) XPS spectra in the C1s, O1s and Fe3p regions for the as-prepared iron carbide sample and after oxygen annealing at $400 \mathrm{~K}$ and $1 \times 10^{-6}$ mbar. The carbide peak intensity has a strong decrease after oxidation, while the $\mathrm{sp}^{2}$ and $\mathrm{sp}^{3}$ peaks present almost no changes. The Fe3p peak shifts to a higher binding energy after oxidation. (d) STM images corresponding to the XPS 
data, showing an oxidized surface. Inset displays the atomic-scale image, which shows the hexagonal oxide structure.

Lastly, we tested the sensitivity of the Fe-C film towards oxygen gas. Figure 8a illustrates the strong decrease of the carbidic C peak after oxidation, with the relative concentration decreasing from $62 \%$ to $34 \%$, while small change in the absolute contribution occurs for of $\mathrm{sp}^{2}$ and $\mathrm{sp}^{3} \mathrm{C}$ on the surface. The O1s peak shown in Figure8b reveals that a small amount of oxides (less than $10 \%$ compared to the fully oxidized sample) is already present in the as-prepared carbide sample after $\mathrm{C}_{2} \mathrm{H}_{4}$ annealing, estimated by the peak intensity. The O1s peak is located at $529.8 \mathrm{eV}$, with a large FWHM, probably due to mixed iron oxide phases. After $\mathrm{O}_{2}$ annealing ( $400 \mathrm{~K}, 1 \times 10^{-6} \mathrm{mbar}$ ), the intensity of the O1s peak increases significantly as illustrated in Figure 8b, indicating the formation of a large amount of iron oxide. Correspondingly, the oxidized sample shows an obvious shift of the Fe3p peak towards higher $\mathrm{BE}$ with respect to the Fe 3p BE of the iron carbide sample. The results show that the Fe carbide film is quite reactive towards oxygen, which is in agreement with earlier experimental and DFT studies, reporting Fe carbides oxidizing with a low energy barrier., ${ }^{62}$ The corresponding STM images in Figure 8d present the morphology changes of the carbide surface after oxidation. Unlike carbidization, oxidation has a dramatic effect on the surface morphology. The rectangular shaped facets are converted into plate-like hexagonal structures, whose atomic structure expose a regular hexagonal lattices in the STM images. The atomic distance measured in the inset of Figure $8 \mathrm{~d}$ is around $3.1 \AA$, consistent with Fe oxides. ${ }^{63-66}$ It is speculated that the carbidic $\mathrm{C}$ reacts selectively with $\mathrm{O}$, desorbing from the surface as $\mathrm{CO}$ or $\mathrm{CO}_{2}{ }^{67}$ A strong reactivity towards oxygen is a general observation for both pure Fe and Fe-C on $\mathrm{Au}(111)$ irrespective of the film thicknesses. The strong sensitivity towards oxygen was even more pronounced for the submonolayer $\mathrm{Fe} / \mathrm{Au}(111)$ samples, which were found to convert into $\mathrm{FeO}$ by 
trace amounts of water in the chamber or oxygen in the ethylene gas by XPS. Based on this finding and the fact that no carbide formation is detected for Fe at less than 2 ML in our XPS data here, we conclude that our previous observations for this system reflect predominantly $\mathrm{FeO}$ rather than carbides. ${ }^{68}$

\section{Conclusions}

In conclusion, we have reported a successful synthesis of well-defined iron carbide films, prepared by atomic $\mathrm{C}$ deposition and by $\mathrm{C}_{2} \mathrm{H}_{4}$ decomposition on $\mathrm{Fe} / \mathrm{Au}(111)$ films. The essential requirement for carbide formation is the phase transformation to a $b c c$ Fe structure in the films. Irrespective of the preparation methods, the formation of carbide on multilayer bcc-type $\mathrm{Fe} / \mathrm{Au}(111)$ films is a facile process at room temperature, showing that the structure is thermodynamically favorable. Elevated temperature is essential for $\mathrm{C}$ diffusion from the surface inwards, preventing the accumulation of graphitic surface $\mathrm{C}$ and facilitating the formation of a well-defined carbide film. For ethylene decomposition, the efficiency is increased at higher temperatures, and a declining trend is observed for carbide surfaces with increasing $\mathrm{C}$ content. From our atom-resolved STM images we deduce that the carbide structure contains C-atoms placed in interstitial sites within the $b c c$ Fe lattice, leading to a perturbed $(2 \times 2)$ reconstructed structure with Fe(110)-like facets. The Fe carbide film has an ideal 20 at\% C content assuming that carbon takes up all such position throughout the film, but due to Fe oxide formation and possible vacancies, the overall carbon content is observed to be lower in the XPS analysis. A reaction study with hydrogen indicates that the $\mathrm{C}$ species in the film are unreactive towards hydrogen at mild reaction conditions at $500 \mathrm{~K}$ or due to the low $\mathrm{C}$ content in the carbide films. We, however, anticipate that additional C species located in the intrinsic vacancies of the Fe film could be the likely candidates for active sites in FTS, since CO dissociation can take place on the pristine 
Fe carbide film even at low temperature. This observation points to intrinsic reactivity of the Fe carbide film for CO activation, which is barely seen for a metal Fe film. The low temperature activity observed here may be similar with CO dissociation on the defect sites reported for a Co(0001) surface. ${ }^{31}$ The synthesized carbide films are extremely reactive to oxygen and water, resulting in the formation of Fe oxides, explaining our previous observations for monolayer structures as $\mathrm{FeO}$ islands rather than carbides. $^{68}$ Since the $(2 \times 2)$ carbide films are thermodynamically stable under vacuum conditions, high-pressure conditions would be required for incorporation of additional, more reactive $\mathrm{C}$ species.

\section{ASSOCIATED CONTENT}

Supporting Information. Estimation of sensitivity factor, the influence of the Fe films thickness on ethylene decomposition, literature reports of C1s binding energies for sp3, sp2 and carbidic carbon in iron carbide samples, STM images showing the general $(2 \times 2)$ reconstructions of the $\mathrm{Fe}(110)$ surface after $\mathrm{C}$ incorporation, line scan profile are provided in the supporting information. This information is available free of charge on the ACS Publications website.

\section{AUTHOR INFORMATION}

\section{Corresponding Author}

*E-mail: jvang@inano.au.dk

\section{ACKNOWLEDGMENT}

Y.L and J.V.L acknowledge support from the Independent Research Fund Denmark Grant no. 4005-00044B. A.A gratefully acknowledges financial support from the Scientific and 
Technological Research Council of Turkey (TUBITAK 2219). Syngaschem BV acknowledges

funding from Synfuels China Technology Co. Ltd.

\section{References}

(1) Fischer, F.; Tropsch, H., The Synthesis of Petroleum at Atmospheric Pressures from Gasification Products of Coal. Brennst.-Chem. 1926, 7, 97-104.

(2) Abello, S.; Montane, D., Exploring Iron-Based Multifunctional Catalysts for Fischer-Tropsch Synthesis: A Review. ChemSusChem 2011, 4, 1538-1556.

(3) de Smit, E.; Cinquini, F.; Beale, A. M.; Safonova, O. V.; van Beek, W.; Sautet, P.; Weckhuysen, B. M., J Am Chem Socmetallurgical and Materials Transactions B-Process Metallurgy and Materials Processing Sciencestability and Reactivity of $\epsilon^{-} \mathrm{X}-\Theta$ Iron Carbide Catalyst Phases in Fischer- Tropsch Synthesis: Controlling Mc. J. Am. Chem. Soc. 2010, 132, 14928-14941.

(4) Schulz, H., Short History and Present Trends of Fischer-Tropsch Synthesis. Appl. Catal., A 1999, 186, 3-12.

(5) Davis, B. H., Fischer-Tropsch Synthesis: Relationship between Iron Catalyst Composition and Process Variables. Catal. Today 2003, 84, 83-98.

(6) de Smit, E.; Weckhuysen, B. M., The Renaissance of Iron-Based Fischer-Tropsch Synthesis: On the Multifaceted Catalyst Deactivation Behaviour. Chem. Soc. Rev. 2008, 37, 2758-2781. (7) Park, E.; Zhang, J. Q.; Thomson, S.; Ostrovski, O.; Howe, R., Characterization of Phases Formed in the Iron Carbide Process by X-Ray Diffraction, Mossbauer, X-Ray Photoelectron Spectroscopy, and Raman Spectroscopy Analyses. Metall. Mater. Trans. B 2001, 32, 839-845. (8) Ding, M.; Yang, Y.; Wu, B.; Li, Y.; Wang, T.; Ma, L., Study on Reduction and Carburization Behaviors of Iron Phases for Iron-Based Fischer-Tropsch Synthesis Catalyst. Appl. Energy 2015, 160, 982-989.

(9) Thüne, P.; Moodley, P.; Scheijen, F.; Fredriksson, H.; Lancee, R.; Kropf, J.; Miller, J.; Niemantsverdriet, J. W., The Effect of Water on the Stability of Iron Oxide and Iron Carbide Nanoparticles in Hydrogen and Syngas Followed by in Situ X-Ray Absorption Spectroscopy. J. Phys. Chem. C 2012, 116, 7367-7373.

(10) Li, S. Z.; Ding, W. P.; Meitzner, G. D.; Iglesia, E., Spectroscopic and Transient Kinetic Studies of Site Requirements in Iron-Catalyzed Fischer-Tropsch Synthesis. J. Phys. Chem. B 2002, 106, 85-91.

(11) Govender, N. S.; de Croon, M. H. J. M.; Schouten, J. C., Reactivity of Surface Carbonaceous Intermediates on an Iron-Based Fischer-Tropsch Catalyst. Appl. Catal., A 2010, 373, 81-89.

(12) Wezendonk, T. A.; Sun, X.; Dugulan, A. I.; van Hoof, A. J. F.; Hensen, E. J. M.; Kapteijn, F.; Gascon, J., Controlled Formation of Iron Carbides and Their Performance in Fischer-Tropsch Synthesis. J. Catal. 2018, 362, 106-117. 
(13) Santos, V. P.; Wezendonk, T. A.; Jaen, J. J.; Dugulan, A. I.; Nasalevich, M. A.; Islam, H. U.; Chojecki, A.; Sartipi, S.; Sun, X.; Hakeem, A. A.; Koeken, A. C.; Ruitenbeek, M.;

Davidian, T.; Meima, G. R.; Sankar, G.; Kapteijn, F.; Makkee, M.; Gascon, J., Metal Organic Framework-Mediated Synthesis of Highly Active and Stable Fischer-Tropsch Catalysts. Nat. Commun. 2015, 6, 6451.

(14) Gracia, J. M.; Prinsloo, F. F.; Niemantsverdriet, J. W., Mars-Van Krevelen-Like Mechanism of Co Hydrogenation on an Iron Carbide Surface. Catal. Lett. 2009, 133, 257-261.

(15) Ozbek, M. O.; Niemantsverdriet, J. W., Elementary Reactions of Co and H2 on CTerminated X-Fe5c2(001) Surfaces. J. Catal. 2014, 317, 158-166.

(16) Ozbek, M. O.; Niemantsverdriet, J. W., Methane, Formaldehyde and Methanol Formation Pathways from Carbon Monoxide and Hydrogen on the (001) Surface of the Iron Carbide XFe5c2. J. Catal. 2015, 325, 9-18.

(17) Herbstein, F.; Snyman, J., Identification of Eckstrom-Adcock Iron Carbide as Fe7c3. Inorg. Chem. 1964, 3, 894-896.

(18) Niemantsverdriet, J.; Van der Kraan, A.; Van Dijk, W.; Van der Baan, H., Behavior of Metallic Iron Catalysts During Fischer-Tropsch Synthesis Studied with Mössbauer Spectroscopy, X-Ray Diffraction, Carbon Content Determination, and Reaction Kinetic Measurements. J. Phys. Chem. 1980, 84, 3363-3370.

(19) Van Der Laan, G. P.; Beenackers, A., Kinetics and Selectivity of the Fischer-Tropsch Synthesis: A Literature Review. Catal. Rev. 1999, 41, 255-318.

(20) Yang, C.; Zhao, H.; Hou, Y.; Ma, D., Fe5c2 Nanoparticles: A Facile Bromide-Induced Synthesis and as an Active Phase for Fischer-Tropsch Synthesis. J. Am. Chem. Soc. 2012, 134, 15814-15821.

(21) Caceres, P. G., Low-Temperature Synthesis of Nanostructured X-Fe5c2 Platelets in Co+H2 Atmospheres. Mater. Charact. 2006, 56, 26-31.

(22) Du Plessis, H. E. Crystal structures of the iron carbides. Ph.D. Thesis, University of Johannesburg, Johannesburg, South Africa, 2008.

(23) Xu, J.; Bartholomew, C. H., Temperature-Programmed Hydrogenation (Tph) and in Situ Mössbauer Spectroscopy Studies of Carbonaceous Species on Silica-Supported Iron

Fischer-Tropsch Catalysts. J. Phys. Chem. B 2005, 109, 2392-2403.

(24) Liu, X.-W.; Cao, Z.; Zhao, S.; Gao, R.; Meng, Y.; Zhu, J.-X.; Rogers, C.; Huo, C.-F.; Yang, Y.; Li, Y.-W.; Wen, X.-D., Iron Carbides in Fischer-Tropsch Synthesis: Theoretical and Experimental Understanding in Epsilon-Iron Carbide Phase Assignment. J. Phys. Chem. C 2017, 121, 21390-21396.

(25) Mohandas, J. C.; Gnanamani, M. K.; Jacobs, G.; Ma, W.; Ji, Y.; Khalid, S.; Davis, B. H., Fischer-Tropsch Synthesis: Characterization and Reaction Testing of Cobalt Carbide. ACS Catal. 2011, 1, 1581-1588.

(26) Lewis, E. A.; Jewell, A. D.; Kyriakou, G.; Sykes, E. C., Rediscovering Cobalt's Surface Chemistry. Phys. Chem. Chem. Phys. 2012, 14, 7215-7224.

(27) Lewis, E. A.; Le, D.; Jewell, A. D.; Murphy, C. J.; Rahman, T. S.; Sykes, E. C. H., Visualization of Compression and Spillover in a Coadsorbed System: Syngas on Cobalt Nanoparticles. ACS Nano 2013, 7, 4384-4392.

(28) Lewis, E. A.; Le, D.; Jewell, A. D.; Murphy, C. J.; Rahman, T. S.; Sykes, E. C., Segregation of Fischer-Tropsch Reactants on Cobalt Nanoparticle Surfaces. Chem. Commun. 2014, 50, 6537-6539. 
(29) Weststrate, C. J.; Kızılkaya, A. C.; Rossen, E. T. R.; Verhoeven, M. W. G. M.; Ciobîcă, I. M.; Saib, A. M.; Niemantsverdriet, J. W., Atomic and Polymeric Carbon on Co(0001): Surface Reconstruction, Graphene Formation, and Catalyst Poisoning. J. Phys. Chem. C 2012, 116, 11575-11583.

(30) Weststrate, C. J.; van de Loosdrecht, J.; Niemantsverdriet, J. W., Spectroscopic Insights into Cobalt-Catalyzed Fischer-Tropsch Synthesis: A Review of the Carbon Monoxide Interaction with Single Crystalline Surfaces of Cobalt. J. Catal. 2016, 342, 1-16.

(31) Weststrate, C. J.; van Helden, P.; van de Loosdrecht, J.; Niemantsverdriet, J. W., Elementary Steps in Fischer-Tropsch Synthesis: Co Bond Scission, Co Oxidation and Surface Carbiding on Co(0001). Surf. Sci. 2016, 648, 60-66.

(32) Navarro, V.; van Spronsen, M. A.; Frenken, J. W., In Situ Observation of Self-Assembled Hydrocarbon Fischer-Tropsch Products on a Cobalt Catalyst. Nat. Chem. 2016, 8, 929-934. (33) Strømsheim, M. D.; Svenum, I.-H.; Farstad, M. H.; Li, Z.; Gavrilovic, L.; Guo, X.; Lervold, S.; Borg, A.; Venvik, H. J., Effects of K Adsorption on the Co-Induced Restructuring of Co (11-20). Catal. Today 2018, 299, 37-46.

(34) Steynberg, P. J.; van den Berg, J. A.; Janse van Rensburg, W., Bulk and Surface Analysis of Hagg Fe Carbide (Fe(5)C(2)): A Density Functional Theory Study. J. Phys.: Condens. Matter 2008, 20, 064238.

(35) Sorescu, D. C., Plane-Wave Density Functional Theory Investigations of the Adsorption and Activation of Co on Fe5c2 Surfaces. J. Phys. Chem. C 2009, 113, 9256-9274.

(36) Cui, X.; Xu, J.; Zhang, C.; Yang, Y.; Gao, P.; Wu, B.; Li, Y., Effect of Pretreatment on Precipitated Fe-Mo Fischer-Tropsch Catalysts: Morphology, Carburization, and Catalytic Performance. J. Catal. 2011, 282, 35-46.

(37) Petersen, M. A.; Cariem, M. J.; Claeys, M.; van Steen, E., A Dft Perspective of Potassium Promotion of Chi-Fe5c2(100). Appl. Catal., A 2015, 496, 64-72.

(38) Over, H.; Kim, Y. D.; Seitsonen, A.; Wendt, S.; Lundgren, E.; Schmid, M.; Varga, P.; Morgante, A.; Ertl, G., Atomic-Scale Structure and Catalytic Reactivity of the Ruo2 (110) Surface. Science 2000, 287, 1474-1476.

(39) Kim, Y. D.; Seitsonen, A. P.; Wendt, S.; Wang, J.; Fan, C.; Jacobi, K.; Over, H.; Ertl, G., Characterization of Various Oxygen Species on an Oxide Surface: Ruo2 (110). J. Phys. Chem. B 2001, 105, 3752-3758.

(40) Wendt, S.; Seitsonen, A. P.; Kim, Y. D.; Knapp, M.; Idriss, H.; Over, H., Complex Redox Chemistry on the Ruo2 (110) Surface: Experiment and Theory. Surf. Sci. 2002, 505, 137-152.

(41) Zhou, X.; Mannie, G. J. A.; Yin, J. Q.; Yu, X.; Weststrate, C. J.; Wen, X. D.; Wu, K.; Yang, Y.; Li, Y. W.; Niemantsverdriet, J. W., Iron Carbidization on Thin-Film Silica and Silicon: A near-Ambient-Pressure X-Ray Photoelectron Spectroscopy and Scanning Tunneling Microscopy Study. ACS Catal. 2018, 8, 7326-7333.

(42) Lægsgaard, E.; Besenbacher, F.; Mortensen, K.; Stensgaard, I., A Fully Automated, 'Thimble - Size’ scanning Tunnelling Microscope. J. Microsc. 1988, 152, 663-669.

(43) Allmers, T.; Donath, M., Growth and Morphology of Thin Fe Films on Flat and Vicinal Au(111): A Comparative Study. New J. Phys. 2009, 11, 103049.

(44) Bulou, H.; Scheurer, F.; Ohresser, P.; Barbier, A.; Stanescu, S.; Quirós, C., Structure of Self-Organized Fe Clusters Grown on Au(111) Analyzed by Grazing Incidence X-Ray Diffraction. Phys. Rev. B 2004, 69, 155413. 
(45) Donati, F.; Fratesi, G.; Passoni, M.; Casari, C. S.; Mairov, A.; Bottani, C. E.; Trioni, M. I.; Bassi, A. L., Strain Effect on Local Electronic Properties of Fe Nanoislands Grown on Au(111). Phys. Rev. B 2011, 83, 153404.

(46) Voigtlander, B.; Meyer, G.; Amer, N. M., Epitaxial-Growth of Fe on Au(111) - a Scanning Tunneling Microscopy Investigation. Surf. Sci. 1991, 255, 529-535.

(47) Vinogradov, N. A.; Zakharov, A. A.; Kocevski, V.; Rusz, J.; Simonov, K. A.; Eriksson, O.; Mikkelsen, A.; Lundgren, E.; Vinogradov, A. S.; Martensson, N.; Preobrajenski, A. B., Formation and Structure of Graphene Waves on Fe(110). Phys. Rev. Lett. 2012, 109, 026101. (48) Vinogradov, N. A.; Simonov, K. A.; Generalov, A. V.; Drnec, J.; Carlà, F.; Vinogradov, A. S.; Preobrajenski, A. B.; Mårtensson, N.; Felici, R., The Structural Evolution of Graphene/Fe(110) Systems Upon Annealing. Carbon 2017, 111, 113-120.

(49) Furlan, A.; Jansson, U.; Lu, J.; Hultman, L.; Magnuson, M., Structure and Bonding in Amorphous Iron Carbide Thin Films. J. Phys.: Condens. Matter 2015, 27, 045002.

(50) Furlan, A.; Lu, J.; Hultman, L.; Jansson, U.; Magnuson, M., Crystallization Characteristics and Chemical Bonding Properties of Nickel Carbide Thin Film Nanocomposites. J. Phys.:

Condens. Matter 2014, 26, 415501.

(51) Wiltner, A.; Linsmeier, C., Formation of Endothermic Carbides on Iron and Nickel. Phys. Status Solidi A 2004, 201, 881-887.

(52) Mattevi, C.; Wirth, C. T.; Hofmann, S.; Blume, R.; Cantoro, M.; Ducati, C.; Cepek, C.; Knop-Gericke, A.; Milne, S.; Castellarin-Cudia, C.; Dolafi, S.; Goldoni, A.; Schloegl, R.; Robertson, J., In-Situ X-Ray Photoelectron Spectroscopy Study of Catalyst-Support Interactions and Growth of Carbon Nanotube Forests. J. Phys. Chem. C 2008, 112, 12207-12213.

(53) Arabczyk, W.; Storbeck, F.; Müssig, H. J., Electron Spectroscopy Studies on Carbon Segregation from a Mono-Crystalline A-Fe(111) Specimen. Appl. Surf. Sci. 1993, 65, 94-98. (54) Wiltner, A.; Linsmeier, C.; Jacob, T., Carbon Reaction and Diffusion on Ni(111), Ni(100), and Fe(110): Kinetic Parameters from X-Ray Photoelectron Spectroscopy and Density Functional Theory Analysis. J. Chem. Phys. 2008, 129, 084704.

(55) Jiang, D. E.; Carter, E. A., Carbon Atom Adsorption on and Diffusion into Fe(110) and Fe(100) from First Principles. Phys. Rev. B 2005, 71, 045402.

(56) Liu, X.-W.; Huo, C.-F.; Li, Y.-W.; Wang, J.; Jiao, H., Energetics of Carbon Deposition on $\mathrm{Fe}(100)$ and $\mathrm{Fe}(110)$ Surfaces and Subsurfaces. Surf. Sci. 2012, 606, 733-739.

(57) Jiang, D. E.; Carter, E. A., Carbon Dissolution and Diffusion in Ferrite and Austenite from First Principles. Phys. Rev. B 2003, 67, 214103.

(58) Esconjauregui, S.; Whelan, C. M.; Maex, K., The Reasons Why Metals Catalyze the Nucleation and Growth of Carbon Nanotubes and Other Carbon Nanomorphologies. Carbon 2009, 47, 659-669.

(59) Erley, W.; Baro, A. M.; Ibach, H., Vibrational Spectra of Acetylene and Ethylene Adsorbed on Fe(110). Surf. Sci. 1982, 120, 273-290.

(60) Sahputra, I. H.; Chakrabarty, A.; Restrepo, O.; Bouhali, O.; Mousseau, N.; Becquart, C. S.; El-Mellouhi, F., Carbon Adsorption on and Diffusion through the Fe(110) Surface and in Bulk: Developing a New Strategy for the Use of Empirical Potentials in Complex Material SetUps. Phys. Status Solidi B 2017, 254, 1600408.

(61) Brodén, G.; Gafner, G.; Bonzel, H. P., A Ups and Leed/Auger Study of Adsorbates on Fe(110). Appl. Phys. 1977, 13, 333-342. 
(62) Yu, L.; Liu, Y.; Yang, F.; Evans, J.; Rodriguez, J. A.; Liu, P., Co Oxidation on GoldSupported Iron Oxides: New Insights into Strong Oxide-Metal Interactions. J. Phys. Chem. C 2015, 119, 16614-16622.

(63) Khan, N. A.; Matranga, C., Nucleation and Growth of Fe and Feo Nanoparticles and Films on $\mathrm{Au}(111)$. Surf. Sci. 2008, 602, 932-942.

(64) Deng, X.; Lee, J.; Wang, C.; Matranga, C.; Aksoy, F.; Liu, Z., In Situ Observation of Water Dissociation with Lattice Incorporation at Feo Particle Edges Using Scanning Tunneling Microscopy and X-Ray Photoelectron Spectroscopy. Langmuir 2011, 27, 2146-2149.

(65) Deng, X. Y.; Matranga, C., Selective Growth of Fe2o3 Nanoparticles and Islands on $\mathrm{Au}(111)$. J. Phys. Chem. C 2009, 113, 11104-11109.

(66) Deng, X.; Lee, J.; Matranga, C., Preparation and Characterization of Fe3o4(111) Nanoparticles and Thin Films on $\mathrm{Au}(111)$. Surf. Sci. 2010, 604, 627-632.

(67) Booyens, S.; Gilbert, L.; Willock, D.; Bowker, M., The Adsorption of Ethene on Fe(111) and Surface Carbide Formation. Catal. Today 2015, 244, 122-129.

(68) Mannie, G. J. A.; Lammich, L.; Li, Y.-W.; Niemantsverdriet, J. W.; Lauritsen, J. V., Monolayer Iron Carbide Films on $\mathrm{Au}(111)$ as a Fischer-Tropsch Model Catalyst. ACS Catal.

2014, 4, 3255-3260.

\section{TOC graphics}

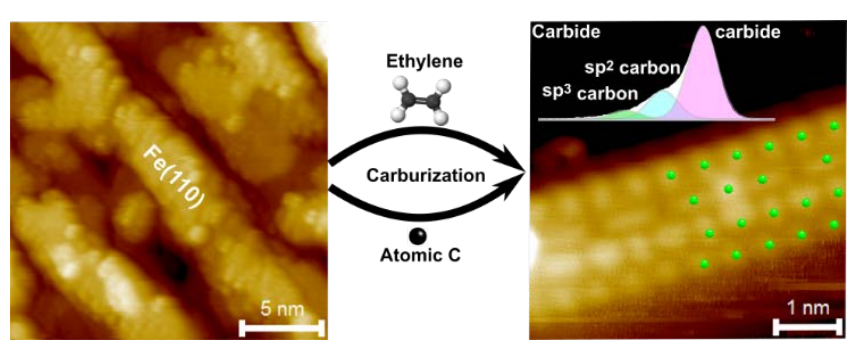

